
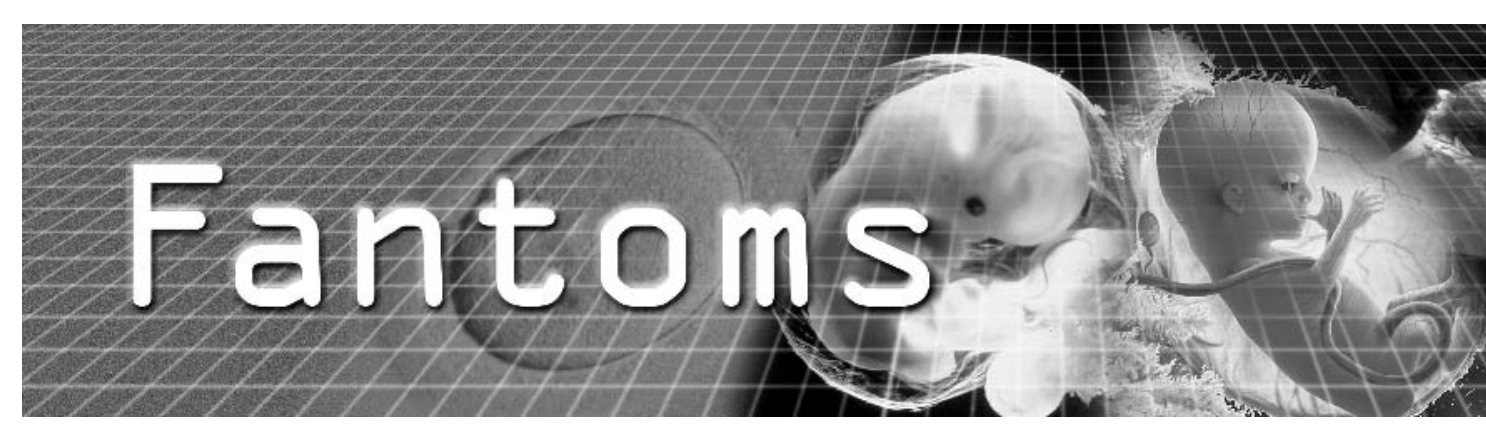

\section{FAMILY AFFAIRS}

Parsons and colleagues studied the families of all nine affected infants and all 10 carrier infants identified by the newborn screening programme for cystic fibrosis after its introduction in Wales. All were in favour of screening. Implications for the wider family were the main problems highlighted. Parents were uncomfortable about not being offered the opportunity to learn the carrier status of their other children. Sharing the information with other family members was problematic, particularly where there were already family tensions. These two unresolved issues are discussed further by Super in the related leading article.

See $p 448$ and p 467

\section{UPDATED META- ANALYSIS OF PROPHYLACTIC INDOMETHACIN}

If you think that PDAs are for storing PDFs then you had better download this one. Prophylactic indomethacin for preterm infants reduces severe intraventricular haemorrhage and symptomatic patent ductus arteriosus (PDA), but trials with adequate follow up now show that despite this it does not change mortality, cerebral palsy, blindness, deafness, severe developmental delay, or bronchopulmonary dysplasia. When the gravitationally disadvantaged lady sings, it is about the importance of long term follow up for randomised trials. See p 464

www.archdischild.com

\section{WEIGHTWATCHERS}

Routine weighing of infants after birth is controversial. McDonald and colleagues find it useful for identifying a population of infants who may be at risk of dehydration and providing their mothers with additional feeding support. Around $10 \%$ of breast fed infants and $2.5 \%$ of formula fed infants in their study lost $10 \%$ of more of their birth weight in the first weeks after birth.

See $\mathrm{p} 472$

\section{MANY UNHAPPY RETURNS}

Of 32 infants in this series from Japan who survived neonatal herpes simplex infection, $13(41 \%)$ had a relapse after the end of acyclovir treatment. Of the 11 infants with type 2 virus infection seven had a relapse. Two infants with localised disease at first presentation had later CNS relapses. Three infants had more than two relapses.

See $p 483$

\section{MOTION ARTEFACT}

Sahni et al evaluated pulse oximetry, comparing a monitor utilising Masimo signal extraction technology to a Nellcor N-200 monitor. They studied oxygen saturation and heart rate in 15 healthy term males who were undergoing circumcision after "non-invasive" analgesia. The infants were sleeping quietly before the procedure. During the circumcision the heart rate of the infants went up considerably and the saturation monitoring was significantly compromised by movement artefact. Makes you wonder whether the analgesia was invasive enough! Artefact and data loss were substantially less with the Masimo monitor.

See p 505

\section{ANNP LED TRANSPORTS}

Those establishing regional transport networks will be interested to read this article by Leslie and Stephenson. Advanced neonatal nurse practitioners (ANNPs)are at it again. This time leading neonatal emergency transports. A series of studies has now shown that ANNPs stay in the job, usually in the unit that provided their training, and once adequately experienced they can provide to a high standard all of the service elements that have traditionally been the remit of trainee paediatricians. Now how do we replenish the nursing establishment?

See p 509

\section{CORRECTION}

I incorrectly implied in a July Fantom that the paper by Marriott et al, Weaning preterm infant: a randomised controlled trial (Arch Dis Child Fetal Neonatal Ed 2003;88:F302-7), was from Southampton. It was of course from Winchester, and I apologise unreservedly for this embarrassing error. Martin Ward Platt 